\title{
STUDI DEFORMASI GUNUNG KELUT DENGAN METODE SURVEI GPS
}

\author{
Hasanuddin Z. Abidin 1), D. Darmawan 1), M. A. Kusuma 1), M. Hendrasto ${ }^{2)}$,
} O.K. Suganda 2), M. Gamal 1), F. Kimata ${ }^{3)}$, C. Rizos ${ }^{4)}$

1) Departemen Teknik Geodesi, Institut Teknologi Bandung (ITB),

Jl. Ganesha 10, Bandung 40132, e-mail : hzabidin@gd.itb.ac.id

2) Direktorat Vulkanologi dan Mitigasi Bencana Geologi, Jl. Diponegoro 57, Bandung

3) Research Center for Seismology and Volcanology, Nagoya University, Nagoya, Japan

4) School of Geomatics Engineering, University of New South Wales, Australia

\begin{abstract}
ABSTRAK
Pemantauan aktivitas gunungapi dapat dilakukan dengan berbagai metode, dimana salah satunya adalah metode deformasi. Pada dasarnya metode ini diterapkan untuk memperoleh pola dan kecepatan deformasi dari tubuh gunungapi, baik dalam arah horisontal maupun vertikal, yang selanjutnya dapat digunakan untuk mengestimasi lokasi serta ukuran dari pusat tekanan penyebab deformasi. Metode deformasi dapat diimplementasikan menggunakan beragam sensor dan teknik, dimana salah satunya adalah teknik yang menggunakan pengamatan terhadap satelit GPS (Global Positioning System). Makalah ini akan menjelaskan penggunaan metode survei GPS secara periodik untuk studi deformasi Gunung Kelut, gunungapi aktif tipe-A yang terletak di Jawa Timur. Vektor pergeseran yang diperoleh dari dua survei GPS yang telah dilaksanakan di kawasan gunung Kelut akan diberikan. Hasil estimasi lokasi pusat tekanan yang berbasiskan model Mogi juga akan disertakan. Makalah akan diakhiri dengan beberapa catatan penutup.
\end{abstract}

\begin{abstract}
Monitoring the activities of volcano could be done by various methods, which one of them is the deformation method. This method is basically used to obtain the pattern and speed of the deformation of the body of volcano, both in horizontal and vertical directions, which in turn could be used to infer the location and size of the pressure source of deformation. It can be implemented by using various sensors and techniques, which one of them is a technique utilizing the observations to the GPS (Global Positioning System) satellites. This paper will describe the use of repeated GPS survey method for studying the deformation of Kelut volcano, a typeA volcano which is located in East Java province. The displacement vectors obtained from two GPS surveys that have been conducted in the area of Kelut volcano will be given. The estimated pressure source based on Mogi model will also be presented. The paper will be sum up with some closing remarks.
\end{abstract}

\section{PENDAhuluan}

Ada beberapa metode pemantauan aktivitas gunung api yang telah diaplikasikan sekarang ini [McGuire et al., 1995; Scarpa \& Tilling, 1996], yaitu antara lain metode seismik, metode deformasi, metode kimia gas, metode termal, dan metode penginderaan jauh (dengan menggunakan sistem video, citra satelit, dan sebagainya). Metode-metode ini akan melibatkan sistem peralatan/sensor tersendiri, dan disamping itu dapat diimplementasikan secara episodik maupun kontinyu.

Metode yang paling banyak digunakan untuk pemantauan gunung api di Indonesia saat ini adalah metode seismik. Metode seismik yang menggunakan sensor seismometer ini 
pada dasarnya digunakan untuk mengevaluasi aktivitas yang terjadi di dalam gunung api. Disamping metode seismik, metode deformasi pun cukup banyak diaplikasikan dalam pemantauan gunung api dengan menggunakan berbagai macam sensor atau sistem, dan metode ini dianggap punya potensi yang sangat besar untuk berkontribusi dalam pemantauan aktivitas gunung api. Metode ini pada dasarnya ingin mendapatkan pola dan kecepatan dari deformasi permukaan gunung api, baik dalam arah horisontal maupun vertikal.

Pada prinsipnya deformasi dari tubuh gunungapi dapat berupa penaikan permukaan tanah (inflasi) ataupun penurunan permukaan tanah (deflasi). Deformasi yang berupa inflasi umumnya terjadi karena proses gerakan magma ke permukaan yang menekan permukaan tanah di atasnya. Dalam hal ini deformasi yang maksimal biasanya teramati tidak lama sebelum letusan gunungapi berlansung. Sedangkan deformasi berupa deflasi umumnya terjadi selama atau sesudah masa letusan. Pada saat itu tekanan magma di dalam tubuh gunungapi telah melemah. Pada saat itu permukaan tanah cenderung kembali ke posisinya semula. Gejala deformasi gunungapi akan menyebabkan pergeseran posisi suatu titik di tubuh gunungapi. Pergeseran posisi tersebut dapat terjadi baik dalam arah horisontal maupun vertikal. Menurut [Van der Laat, 1996], nilai pergeseran ini bisa mencapai puluhan meter pada gunungapi silisik yang membentuk kubah lava. Pada gunungapi yang kantong magmanya masih jauh di bawah permukaan atau gerakan naiknya magma relatif lambat, deformasi yang teramati relatif kecil, kadang-kadang nilai strain nya lebih kecil dari $0.1 \mathrm{ppm} /$ tahun.

Pemantauan deformasi suatu gunungapi dapat dilakukan dengan menggunakan berbagai macam sensor atau sistem. Metode deformasi ini pada dasarnya ingin mendapatkan pola dan kecepatan dari gerakan tubuh gunungapi, baik dalam arah horisontal maupun vertikal. Menurut [McGuire, 1995], data dan informasi deformasi permukaan ini dapat digunakan untuk mengungkapkan beberapa hal tentang karakteristik dari aktivitas magmatik gunungapi yang bersangkutan, seperti : perubahan dari fluks magma (untuk kantong magma yang bersifat tetap), serta lokasi, bentuk, dan perkembangan kantong magma baru yang terbentuk karena proses intrusi.

Pemantauan deformasi gunung api dengan metode deformasi umumnya dapat diklasifikasikan atas dua tipe, yaitu metode episodik dan metode kontinyu. Pada metode episodik, pemantauan dilakukan secara berkala dalam selang waktu tertentu. Metode deformasi episodik ini umumnya menggunakan data-data pengamatan terestris, seperti jarak (dari EDM, Electronic Distance Measurement), arah (dari theodolit), beda tinggi (dari sipat datar), dan perubahan gaya berat (dari pengukuran mikrogravitas); dan sekarang ini juga mulai menggunakan data pengamatan GPS dan juga INSAR (Interferometric Synthetic Aperture Radar). Sedangkan pada metode deformasi kontinyu pemantauan dilakukan terus menerus secara otomatis. Metode deformasi kontinyu ini umumnya menggunakan sensor-sensor tiltmeter, extensiometer, dan dilatometer, yang hanya mengkarakterisir deformasi yang sifatnya relatif lokal. Patut ditekankan di sini bahwa GPS yang dikombinasikan dengan sistem telemetri/komunikasi data juga mulai banyak digunakan untuk memantau deformasi gunung api secara kontinyu.

Baik untuk metode episodik maupun kontinyu, dapat diperkirakan bahwa GPS [Abidin, 2000] akan punya peran yang penting dalam proses pemantauan deformasi gunung api di masa-masa mendatang. Untuk gunung-gunung api yang lebih aktif, sehubungan dengan adanya tuntutan ketersediaan informasi deformasi dalam waktu yang relatif cepat, maka pemantauan secara kontinyu dengan GPS akan lebih efektif dibandingkan dengan penggunaan metode survai GPS. Makalah ini akan menjelaskan penggunaan metode survei GPS secara periodik untuk studi deformasi gunung Kelut. 


\section{GUNUNG KELUT}

Gunung Kelut adalah gunungapi strato aktif yang mempunyai danau kawah di puncaknya. Gunungapi ini terletak di dalam tiga wilayah kabupaten, yaitu Kab. Kediri, Kab. Blitar, dan Kab. Malang di propinsi Jawa Timur. Ketinggian puncak dan danau kawahnya adalah masing-masing sekitar $1731 \mathrm{~m}$ dan $1114 \mathrm{~m}$ di atas permukaan laut [Direktorat Vulkanologi, 1992]. Pada awalnya danau kawah G. Kelut berisi 38 juta $\mathrm{m}^{3}$ air, dan sesudah dialirkan melalui terowongan Ampera volumenya menjadi sekitar 4.5 juta $\mathrm{m}^{3}$ air. Bentuk fisik dari gunung Kelut ditunjukkan pada Gambar 1.

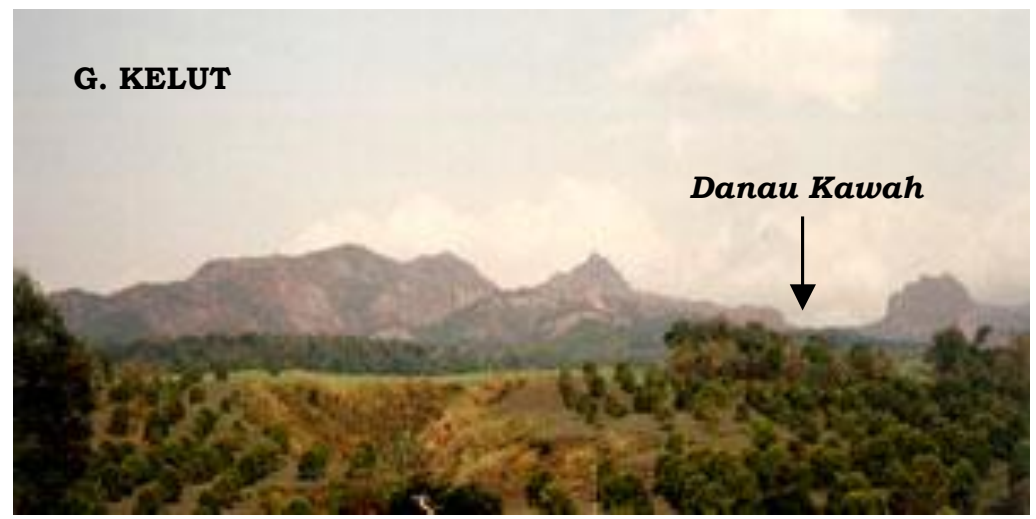

Gambar 1. Gunung Kelut dilihat dari pos pengamatan.

Dalam sejarahnya, G. Kelut sudah kerap meletus. Letusan yang tercatat adalah mulai tahun 1000 dan yang terakhir pada tahun 1990. Letusan-letusan yang tercatat menimbulkan korban adalah : pada tahun 1586 menelan korban sekitar 10.000 jiwa, tahun 1919 menelan korban sekitar 5160 jiwa, tahun 1951 sebanyak 7 korban jiwa, dan tahun 1966 menelan 210 korban jiwa. Letusan terakhir adalah pada tanggal 10 Februari 1990 dengan 34 korban jiwa.. Pada pertengahan Januari 2001, suhu air kawah gunung Kelut meningkat menjadi $51^{\circ} \mathrm{C}$ dari suhu normalnya berkisar sekitar $37-38^{\circ} \mathrm{C}$. Peningkatan suhu sebenarnya sudah dimulai sejak November 2000; tapi peningkatan secara drastis baru mulai 19 Januari 2001.

Aktivitas gunung Kelut di-pantau secara kontinyu dengan perangkat seismograph dari pos pengamatannya yang terletak di desa Margomulyo, yang berjarak sekitar $6 \mathrm{~km}$ dari kawah G. Kelut. Pengukuran temperatur danau ka-wah juga kerap dilakukan sebagai bagian dari proses pemantauan aktivitas gunung Kelut. Deformasi dari tubuh gunung api dan kawa-san sekitarnya juga telah mulai dipelajari dengan menggunakan pengamatan sipat datar (leveling), EDM, dan survei GPS.

\section{SURVEI GPS DI GUNUNG KELUT}

Survei GPS untuk pemantauan deformasi G. Kelut telah dilaksanakan dua kali, yaitu pada 12 Mei 1999 dan 8-9 Februari 2001. Jaring GPS yang disurvei terdiri atas 8 titik seperti yang ditunjukkan pada Gambar 2 berikut. Titik BAIR digunakan sebagai titik referensi, dan dalam analisa deformasi dianggap sebagai titik stabil yang tidak mengalami deformasi. Pengukuran dilaksana-kan oleh tim dari Jurusan Teknik Geodesi ITB dan Direktorat Vulkanologi dan Mitigasi Bencana Geologi. 


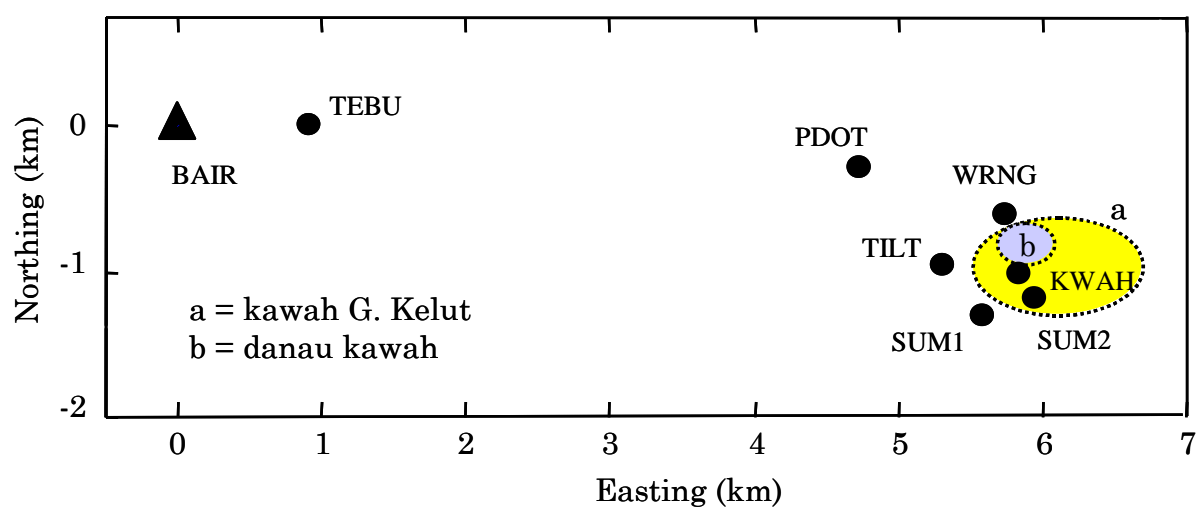

Gambar 2. Stasion-stasion pengamatan GPS di G. Kelut.

Survei yang pertama dilaksanakan pada tanggal 12 Mei 1999 dengan menggunakan 8 receiver GPS tipe geodetik dua frekuensi, yaitu 4 buah receiver Ashtech ZXII-3 dan 4 buah receiver Leica System 300. Pengamatan dilaksanakan dalam satu sesi pengamatan dengan menggunakan 8 receiver GPS yang beroperasi secara simultan, dan lama pengamatan di setiap titik berkisar antara 6 sampai 8 jam. Sedangkan survei kedua dilaksanakan menggunakan 5 receiver GPS tipe geodetik dua-frekuensi, yaitu tiga sistem Ashtech Z-XII3 dan dua sistem Leica System 300. Pengamatan dilakukan dalam dua sesi pengamatan, yang panjang sesinya berkisar antara 12 sampai 24 jam.

\section{PENGOLAHAN DATA GPS DAN HASIL}

Pengolahan data kedua survei GPS dilakukan dengan menggunakan perangkat lunak ilmiah BERNESSE 4.2 [Rothacher \& Mervart, 1996). Pengolahan dilakukan secara radial dari titik BAIR. Titik BAIR digunakan sebagai titik referensi untuk perhitungan, dan koordinatnya ditentukan dari titik BAKOSURTANAL di Cibinong yang merupakan titik geodetik orde-0 dari Jaring Kerangka Geodetik Nasional. Untuk seluruh perhitungan digunakan orbit satelit yang teliti (precise ephemeris), dan residu dari bias troposfir dan ionosfir di estimasi dalam proses perhitungan. Semua ambiguitas fase dapat ditentukan dengan baik, dan solusi akhir koordinat ditentukan dengan menggunakan data fase narrow-lane [Abidin, 2000].

\subsection{Vektor Pergeseran}

Vektor pergeseran suatu titik diperoleh dari selisih koordinat titik yang bersangkutan yang diperoleh dari dua survei GPS yang berturutan. Pada kasus survei GPS di kawasan gunung Kelut ini, vektor pergeserandari titik-titik dalam jaringan pe-mantau berikut deviasi standar nya diberikan pada Tabel 1 beri-kut.. Vektor pergeseran $(\mathrm{dN}, \mathrm{dE}$, dU) diberikan dalam sistem koordinat toposentrik, dengan komponen-komponen koordinat-nya : Northing (N), Easting (E), dan Up (U). Arah pergeseran titik dalam arah horisontal dan vertikal tersebut, divisualisasikan pada Gambar 3 dan 4 berikut.

Tabel 1. Vektor Pergeseran Titik-Titik Jaring GPS

Pemantau Deformasi Gunung Kelut (satuan : cm)

\begin{tabular}{|l|c|c|c|c|c|c|}
\hline \multicolumn{1}{|c|}{ STA } & $\mathbf{d N}$ & $\boldsymbol{\sigma} \mathbf{( d N )}$ & $\mathbf{d E}$ & $\boldsymbol{\sigma}(\mathbf{d E})$ & $\mathbf{d U}$ & $\boldsymbol{\sigma}(\mathbf{d U})$ \\
\hline KAWH & 0.83 & 0.31 & -0.84 & 0.18 & 5.97 & 0.20 \\
\hline WLRG & 1.81 & 0.18 & -1.05 & 0.10 & -2.98 & 0.11 \\
\hline PDOT & 2.06 & 0.16 & -1.14 & 0.10 & -0.43 & 0.10 \\
\hline SUM1 & 0.70 & 0.23 & -1.50 & 0.13 & -2.25 & 0.13 \\
\hline SUM2 & -0.31 & 0.32 & 6.01 & 0.19 & 18.02 & 0.21 \\
\hline TEBU & 0.93 & 0.17 & 0.09 & 0.10 & 2.31 & 0.11 \\
\hline TILT & 0.92 & 0.21 & -1.21 & 0.12 & -1.39 & 0.13 \\
\hline
\end{tabular}


Dari Gambar 3 terlihat bahwa pada periode Mei 1999 dan Februari 2001, pergeseran horisontal titik-titik dari jaringan GPS berkisar antara 2 sampai dengan $6 \mathrm{~cm}$, dengan titik-titik sekitar kawah mengalami pergeseran horisontal yang relatif paling besar. Gambar 3 ini juga mengindikasikan terjadinya proses inflasi di sekitar kawah G. Kelut.

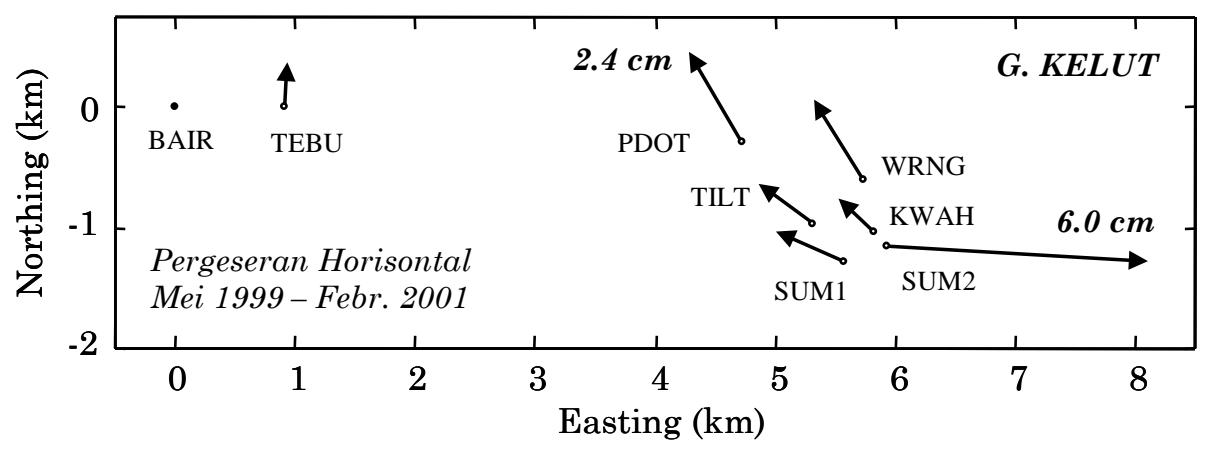

Gambar 3. Vektor Pergeseran Horisontal dari Titik-Titik Jaring GPS Pemantau Deformasi G. Kelut.

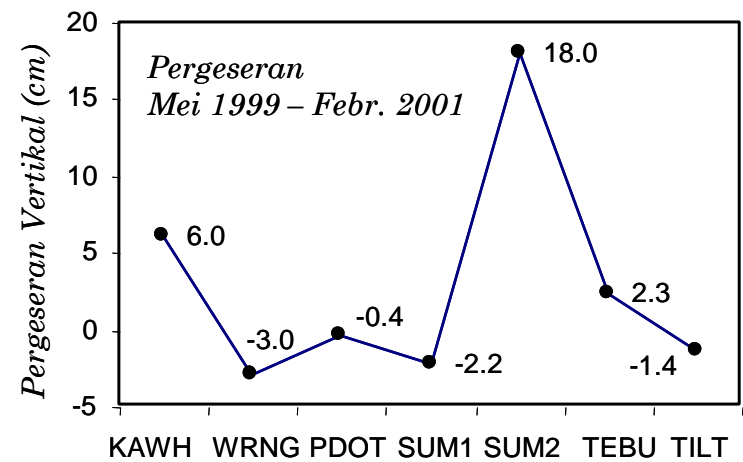

Gambar 4. Vektor Pergeseran Vertikal dari Titik-Titik Jaring GPS Pemantau Deformasi G. Kelut.

Kalau kita bandingkan Gambar 3 dan Gambar 4 terlihat bahwa pergeseran vertikal dari titik-titik dalam jaringan GPS Kelut ini, relatif lebih besar dibandingkan pergeseran horisontalnya. Menarik juga untuk dicatat dari Gambar 4, bahwa pada periode Mei 1999 sampai Febr. 2001 ini, titik SUM2 mengalami pergeseran vertikal sampai sekitar $18 \mathrm{~cm}$. Penyebab dari pergeseran titik SUM2 yang cukup besar ini, baik dalam arah horisontal maupun vertikal, sedang dalam penelaahan lebih lanjut. Dalam hal ini, seandainya pergeseran yang besar ini dianggap karena proses pengolahan data GPS yang belum optimal, maka residu kesalahan troposfir serta efek multipath merupakan faktor-faktor penyebab yang dapat dicurigai.

\subsection{Lokasi Pusat Tekanan}

Dalam konteks deformasi gunungapi, data vektor pergeseran titik-titik pada tubuh gununapi yang bersangkutan dapat digunakan untuk menentukan karakteristik (seperti lokasi) dari pusat tekanan penyebab terjadinya pergeseran posisi titik-titik tersebut. Dalam hal ini model Mogi [Mogi, 1958], yang diilustrasikan pada Gambar 5, umum digunakan untuk menentukan lokasi dari pusat tekanan tersebut. 


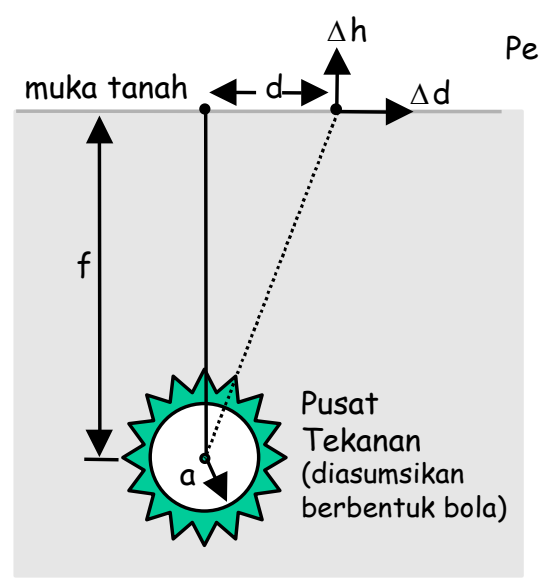

Pergeseran horisontal $(\Delta d)$ dan vertikal $(\Delta h)$ :

Gambar 5. Deskripsi dari Model Mogi [Mogi, 1958].

Perlu ditekankan di sini bahwa dalam penentuan pusat tekanan yang hasilnya ditunjukkan pada Gambar 5 ini, pendekatan dari Nishi et al. (1999) digunakan dalam implementasi model Mogi. Pada pendekatan Nishi ini, yang digunakan sebagai kriteria untuk pencarian lokasi posisi pusat tekanan yang paling sesuai dengan pola vektor pergeseran titik-titik adalah kesesuaian antara perubahan panjang baseline yang diamati dengan perubahan panjang baseline yang dihitung dengan model Mogi.

Pada pendekatan Nishi, perubahan panjang baseline $\left(\Delta \mathrm{L}_{12}\right)$ antara titik-1 $\left(\mathrm{x}_{1}, \mathrm{y}_{1}\right)$ dengan titik-2 $\left(\mathrm{x}_{2}, \mathrm{y}_{2}\right)$ dihitung dengan formula berikut [Nishi et al., 1999] :

$$
\Delta \mathrm{L}_{12}=\frac{\left(\mathrm{x}_{2}-\mathrm{x}_{1}\right) \cdot \mathrm{X}_{12}+\left(\mathrm{y}_{2}-\mathrm{y}_{1}\right) \cdot \mathrm{Y}_{12}}{\mathrm{R}_{1}^{3} \cdot \mathrm{R}_{2}^{3} \cdot \mathrm{L}_{12}} \cdot \mathrm{k}
$$

Pada persamaan (1) di atas :

$$
\begin{array}{ll}
\mathrm{R}_{\mathrm{i}}=\left\{\left(\mathrm{x}_{\mathrm{i}}-\mathrm{x}\right)^{2}+\left(\mathrm{y}_{\mathrm{i}}-\mathrm{y}\right)^{2}+\mathrm{z}^{2}\right\}^{1 / 2},(\mathrm{i}=1,2), & \mathrm{k}=3 \mathrm{a}^{3} \cdot \mathrm{p} /(4 \mu) \\
\mathrm{X}_{12}=\left(\mathrm{x}_{2}-\mathrm{x}\right) \cdot \mathrm{R}_{1}^{3}-\left(\mathrm{x}_{1}-\mathrm{x}\right) \cdot \mathrm{R}_{2}^{3}, & \mathrm{~L}_{12}=\text { panjang baseline antara titik } 1 \text { dan } 2 \\
\mathrm{Y}_{12}=\left(\mathrm{y}_{2}-\mathrm{y}\right) \cdot \mathrm{R}_{1}^{3}-\left(\mathrm{y}_{1}-\mathrm{y}\right) \cdot \mathrm{R}_{2}^{3}, & (\mathrm{x}, \mathrm{y}, \mathrm{z})=\text { koordinat dari lokasi pusat tekanan }
\end{array}
$$

Selanjutnya lokasi pusat tekanan dicari dengan meminimalkan fungsi berikut :

$$
\chi^{2}=\sum_{\mathrm{i}=1}^{\mathrm{N}}\left(\frac{\Delta \mathrm{L}_{\mathrm{i}}^{\mathrm{obs}}-\Delta \mathrm{L}_{\mathrm{i}}^{\mathrm{cal}}}{\sigma_{\mathrm{i}}}\right)
$$

dimana $\Delta \mathrm{L} 12^{\text {obs }}$ dan $\Delta \mathrm{L} 12^{\text {calc }}$ adalah perubahan panjang baseline yang diamati dan dihitung, dan $\sigma_{i}$ adalah deviasi standar dari perubahan panjang baseline yang diamati.

Dengan mengasumsikan bahwa vektor pergeseran yang diperoleh dari survei GPS tersebut di atas merepresentasikan deformasi aktual yang dialami oleh gunung Kelut, maka model Mogi dapat digunakan untuk mengestimasi lokasi dari pusat tekanan penyebab deformasi tersebut. Hasil yang diperoleh ditunjukkan pada Gambar 6 berikut. 


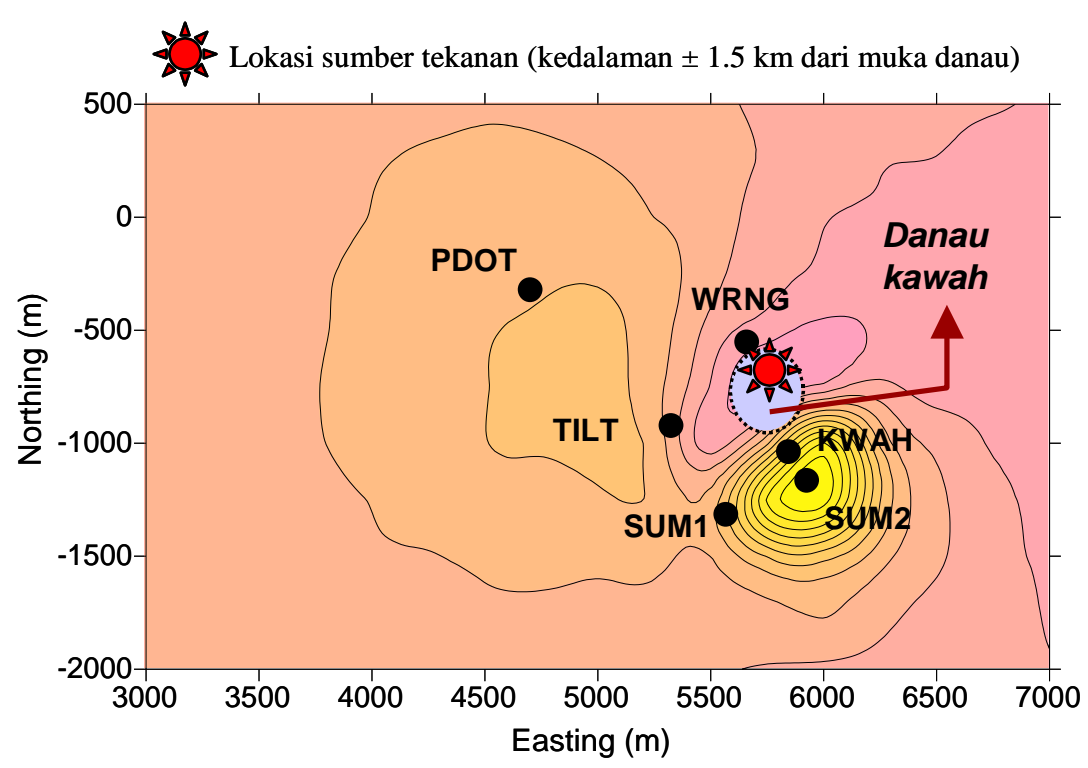

Gambar 6. Hasil estimasi lokasi pusat tekanan gunung Kelut

(kontur merepsentasikan nilai minimum dari $\chi \square$ pada persamaan 2 sebelumnya)

Dari Gambar 6 ini terlihat bahwa secara umum, pada periode pengamatan Mei 1999 Febr. 2001, hasil estimasi menunjukkan bahwa pusat tekanan berada di bawah danau kawah gnung Kelut dengan kedalaman sekitar $1.5 \mathrm{~km}$ di bawah permukaan danau. Lokasi pusat tekanan ini berada di bawah bualan air danau kawah gunung Kelut, yang pada saat survei GPS kedua (Febr. 2001) teramati berada pada tepian sebelah Utara dari danau kawah.

\section{CATATAN PENUTUP}

Metode survei GPS mempunyai kemampuan untuk memantau deformasi gunungapi dengan ketelitian relatif (vektor pergeseran titik) yang cukup tinggi, yaitu sampai level presisi samapai beberapa $\mathrm{mm}$. Meskipun begitu, pencapaian tingkat ketelitian yang tinggi ini bukanlan suatu hal yang mudah. Untuk mencapai tingkat kepresisian $\mathrm{mm}$ tersebut diperlukan penggunaan receiver GPS tipe geodetik dua-frekuensi, perencanaan survei yang cermat, strategi pengamatan yang ketat, serta strategi pengolahan data yang baik dengan memanfaatkan perangkat lunak ilmiah untuk pengolahan datanya. Dengan kemampuannya untuk memantau sinyal deformasi pada tingkat ketelitian yang cukup tinggi tersebut, maka studi deformasi gunung Kelut dengan menggunakan metode survei GPS ini akan terus dilanjutkan, disamping juga studi deformasi gunung-gunungapi lainnya yang juga tengah dilakukan oleh tim peneliti, yaitu gunung-gunung Guntur, Papandayan, Batur, Bromo, dan Anak Krakatau.

Dalam konteks kegiatan studi deformasi gunung Kelut ini, disamping melanjutkan pelaksanaan metode survei GPS, korelasi antara karakteristik deformasi yang diperoleh dari GPS dengan karakteristik geologis, magmatis, dan hidrologis dari gunung Kelut dan kawasan sekitarnya, juga akan ditelaah. Disamping itu integrasi hasil survei GPS dengan hasil survei EDM dan sipat datar di kawasan gunung Kelut juga tengah dilakukan. Penerapan metode INSAR (Interferometric Synthetic Aperture Radar) untuk mendapatkan medan deformasi yang secara spasial lebih menyeluruh juga tengah dipertimbangkan. 


\section{Ucapan Terima Kasih}

Penelitian ini dapat terlaksana berkat adanya kerjasama dan dukungan dari Direktorat Vulkanologi dan Mitigasi Bencana Geologi (DVMBG) dengan Jurusan Teknik Geodesi ITB. Dalam hal ini kami ucapkan banyak terima kasih pada Dr. Achmad D. Wirakusumah dan Dr. Mas Atje Purbawinata dari DVMBG, untuk dukungan administratif sekaligus dukungan moralnya bagi kerjasama ini. Ucapan terima kasih yang khusus juga perlu kami sampaikan pada para pengamat gunung Kelut, yaitu pak Chairul dan pak Yusuf, serta 'armada ojeg gunung Kelut' yang telah banyak membantu tim peneliti dalam suksesnya pelaksanaan survei GPS di kawasan gunung Kelut.

\section{DAFTAR PUSTAKA}

Abidin, H.Z. (2000). Penentuan Posisi Dengan GPS dan Aplikasinya. P.T. Pradnya Paramita, Jakarta. Edisi ke 2. ISBN 979-408-377-1. 268 pp.

Direktorat Vulkanologi (1992). Gunung Kelut. Berita Berkala Vulkanologi, Edisi Khusus No. 172 ..

McGuire, W.J. (1995). "Monitoring active volcanoes - an introduction", In Monitoring Active Volcanoes by B. McGuire, C.R.J. Kilburn, and J. Murray (Eds), pp. 1-31, UCL Press Limited, London, $421 \mathrm{pp}$.

McGuire B., C.R.J. Kilburn, and J. Murray (Eds) (1995) Monitoring Active Volcanoes, UCL Press Limited, London, 421 pp.

Mogi, K. (1958). Relation between the eruption of various volcanoes and the deformation of the ground surface around them. Bulletin of Earthquake Research Institute, Vol. 36, pp. 99-134.

Nishi,K., H. Ono, H. Mori (1999). Global Positioning System measurements of ground deformation caused by magma intrusion and lava discharge: the 1990-1995 eruption at Unzendake volcano, Kyushu, Japan. Journal of Volcanology and Geothermal Research, Volume 89, Nos. 1-4, pp. 23-34.

Rothacher. M. and L. Mervart (Eds.) (1996). Bernesse GPS Software version 4.0. Astronomical Institute. University of Berne. September. 418 pp.

Scarpa, R. and R.I. Tilling (Eds.) (1996). Monitoring and Mitigation of Volcano Hazards. Springer Verlag, Berlin, 841 pp.

Van der Laat, R. (1996) "Ground-Deformation Methods and Results." In Monitoring and Mitigation of Volcano Hazards by R. Scarpa and R.I. Tilling (Eds.), Springer Verlag, Berlin, pp. $147-168$. 